\title{
Comparative Study of Physical Properties of Polymer Composites Reinforced with Uncarbonised and Carbonised Coir
}

\author{
F. O. Aguele' ${ }^{1}$, C. I. Madufor ${ }^{2}$, K. F. Adekunle ${ }^{1}$ \\ ${ }^{1}$ Chemical Engineering Department, Michael Okpara University of Agriculture, Umudike, Nigeria \\ ${ }^{2}$ Polymer and Textile Engineering Department, Federal University of Technology, Owerri, Nigeria \\ Email: aguelefelix@yahoo.com
}

Received 10 June 2014; revised 10 July 2014; accepted 23 July 2014

Copyright (C) 2014 by authors and Scientific Research Publishing Inc. This work is licensed under the Creative Commons Attribution International License (CC BY). http://creativecommons.org/licenses/by/4.0/

(c) (i) Open Access

\section{Abstract}

This study involved the use of uncarbonised and carbonised coir in preparing composites of a given polymer. In this case natural rubber (NR) was used. Uncarbonised coir (UC) and carbonised coir (CC) were separately used to prepare the polymer composites. Carbon black (CB) was also used differently and the filler loadings for all varied between 0 and $50 \mathrm{phr}$. Before using the uncarbonised coir and carbonised coir, they were characterised on the basis of moisture content, $\mathrm{pH}$, particles size and surface area. The properties of the various composite samples prepared were then investigated. The results of the tests obtained for the NR-UC composites were compared with those of NR-CC and also with those of NR-CB composites. It was observed that for hardness, the results obtained from composites of UC and CC fillers showed similar trends with those of carbon black (CB) reinforced composites, increasing with increase in filler volume. For the tensile strength and modulus a trend of slight rise was observed. There were no sharp rises in values as filler volumes were increased. UC and CC fillers were observed to impart very poorly on the tensile strength and modulus relative to the $\mathrm{CB}$ reinforced composites. The results from test for elongation, compression set and flex fatigue showed a falling trend for all the fillers to a comparable level with CB. It was generally observed that the uncarbonised coir presented better potentials for reinforcement than the carbonised coir.

\section{Keywords}

Polymer, Composites, Reinforcing, Fillers, Coir and Vulcanisation

\section{Introduction}

Application of polymers in many areas has been known for a long time. Over the years, the popularity and de-

How to cite this paper: Aguele, F.O., Madufor, C.I. and Adekunle, K.F. (2014) Comparative Study of Physical Properties of Polymer Composites Reinforced with Uncarbonised and Carbonised Coir. Open Journal of Polymer Chemistry, 4, 73-82. 
mands for this class of materials have experienced a steady growth, especially in recent times. Wood, leather, wool and cotton have been in use for various purposes [1].

Rubbers are organic polymer materials which can be stretched to about $200 \%$ of its original length and snap back to the original length immediately the deforming force is removed [2]. To be able to perform effectively in various application areas, rubbers need to possess some basic properties. In their pure states they have no reasonable engineering applications. This is why appropriate compounding and subsequent vulcanisation are done in order to obtain good processing characteristics and desired properties of finished products [2] [3]. This led to the advent of polymer composites of various components and compositions.

A composite, can be generally defined as a combination of two or more components differing in form or composition on a macroscale, having recognisable interfaces between its distinct phases [4] [5]. Composites usually consist of a reinforcing material embedded in a continuous phase, the matrix also called binder. The effective method to increase the strength and to improve overall properties is usually by incorporating dispersed phases into the matrix, which can be an engineering material such as ceramic, metal or polymer [6].

Considerable efforts have been on in the quest for materials that can serve as fillers for reinforced polymer composites besides the commonly used carbon black, calcium carbonate and China clay. Such alternative sources include renewable agricultural by products, like jute, raffia, coconut fibre, flax, wood fibre, rice husk, groundnut shell, rubber seed shell, etc. [3] [7]-[10]. The instability of prices of crude oil and its derivatives is giving concerns in the industry and that has triggered the search for fillers that are obtainable from other sources [11].

This paper comparatively investigates the effects of UC and CC as fillers from renewable source on the reinforcing properties of vulcanized NR composites, vis-a-vis those of CB reinforced composites. During this study, the following were done:

1) Rubber composites were separately prepared using uncarbonised coir (UC) and carbonised (CC) coir differently as fillers.

2) Another set of rubber composites was prepared with carbon black (CB) as filler.

3) The physical properties of the three sets of rubber composites were investigated.

4) Effects of the UC, CC and CB fillers on physical properties of the rubber composites were compared.

Fillers and their influences on rubber products cannot be put aside with a wave of hands, considering the fact that virtually no rubber articles have value without fillers [3] [12].

Though rubbers have unique behaviours which include their ability to stretch to a number of times beyond original length, exhibit high strength and modulus while stretched and to retract rapidly to recover fully on release of the deforming stress, there are structural requirements needed of their molecules to enable them to possess those properties stated above. They must be:

- Polymers with high molecular mass.

- Polymers with a network of cross-links to restrain gross mobility of chains.

- Above their glass transition temperature $\left(\mathrm{T}_{\mathrm{g}}\right)$ at ambient temperatures.

- Amorphous in their unstretched state but preferably develop crystallinity on stretching [2] [13].

Based on the need to contain a network of cross links, it is mandatory that rubbers be vulcanised to introduce the crosslink network before it can actually be available for any meaningful application.

Rubbers can either be natural or synthetic, depending on its origin. The natural rubbers are obtained from various species of trees and shrubs by tapping. It is a naturally occurring hydrocarbon polymer made up of 2-methyl-1, 3-butadiene, also called isoprene, as the repeat unit and about 200 species of plants and shrubs have been identified to produce natural rubber latex [2] [14]. On the other hand, those synthesised via chemical processes are referred to as synthetic rubbers.

Natural rubber is known to have a high green strength ranging between $15 \mathrm{mNm}^{-2}$ and $20 \mathrm{mNm}^{-2}$ in its unfilled state [3]. This unique strength relies on its ability to crystallise when stretched, giving high tensile strength in the direction of elongation [14]. This produces a superior form of reinforcement as it limits the movement between neighbouring molecular chains and leads to increase in hysteresis and ultimate strength [15].

\section{Fillers}

Fillers are solid additives, which are added to rubbers to either act as cheapeners or to enhance the physical properties of vulcanisates and to some extent, the chemical properties too [2] [13] [16] [17]. 
The use of fillers in rubbers is almost as old as the use of rubber itself. For instance, as far back in 1904, carbon black was already discovered and known as the most important powder used in rubber compounding [18]. Fillers in rubber composites help to meet application expansion, since the physical properties (such as hardness and modulus) achievable by vulcanisation alone are limited. Fillers constitute the second largest materials in rubber composites in terms of quantity.

Fillers can be classified on different bases, leading to types, such as inert, reinforcing, particulate, resinous and fibrous fillers [3] [13] [18].

The reinforcing fillers improve the physical and mechanical properties of rubber vulcanisate. The most important reinforcing particulate fillers used in rubber compounds are carbon blacks. Other reinforcing fillers include non-blacks such as silica, aluminum silicate and calcium sulphate.

Some factors, which greatly influence the interaction between a given rubber and particulate filler have been given as extensity, intensity and geometrical factors [18]. The particle size and chemical nature of the fillers' surface influence the reinforcement ability of fillers. It has been found that the finer the particles, the higher the reinforcement properties offered [2] [13] [16]. The cheapeners (diluents) cause reduction in the physical and mechanical properties. Their particle sizes are generally large, ranging between $600 \AA$ and above. Below are some particulate fillers with arrow showing their order of increasing reinforcement [3]:

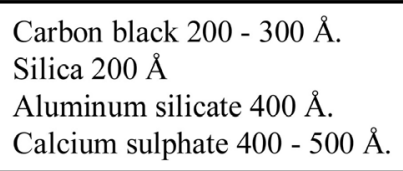

The surface area of particles is directly related to the particle size. If for instance, all particles are assumed to be spheres of the same size, the surface area as per gram of filler is given by:

$$
A_{s}=\frac{\pi d^{2}}{(1 / 6) \pi \rho d^{3}}=\frac{6}{\rho d}
$$

where $d$ = Diameter of particle; $\rho=$ Density of filler

Put in the preferred units for surface area $\left(\mathrm{m}^{2} / \mathrm{g}\right)$ and diameter (nm or $10^{-9} \mathrm{~m}$ ), Equation (1) becomes:

$$
A_{s}=\frac{6000}{\rho d}
$$

Using this information, it is possible to estimate the surface area available for reaction knowing the average particle size of the given filler.

Various researchers have worked extensively on different materials in the search for possible complements or substitute for some grades of carbon black as fillers for rubber products. These researches are receiving more attention today, with focus on biomaterials, which have little or no negative effects on environment. For instance, by-products from agricultural sources have been used-maize cobs, rubber seed shell, ground nut husk, cassava peeling, plantain peel, coir fibre, rubber seed shell carbon, etc. [7] [10] [19]-[21]. In this study, coir and its carbonised product were analysed as fillers in rubber composites.

\section{Experimental}

\subsection{Materials and Methods}

The polymer material used in this study was natural rubber (NR). Natural rubber crumb of grade NSR-10 (Nigeria Standard Rubber) was obtained from KB Rubber Industry Sapele, Delta State. This rubber grade also conforms to TSR-10 (Technically Specified Rubber). Coir was obtained from Agbede in Edo State. Carbon black (N330 HAF) was obtained from Jonaz industrial chemical sales outlet in Benin. The carbon black was used as control in this study.

Other compounding ingredients and additives used are presented in the formulation shown in Table 1 below. These compounding agents are of chemical grade and commercially available and were obtained from various chemical out lets (Jonaz industrial chemicals, Stinpex chemicals and Ally industrial chemicals) in Benin City, Edo state. 
Table 1. Formulations for reinforced natural rubber composites.

\begin{tabular}{cc}
\hline Ingredient & Content (phr) \\
\hline Natural rubber & 100 \\
Zinc oxide & 5.0 \\
Stearic acid & 2.5 \\
Trimethylquinoline (TMQ) & 1.0 \\
Processing oil & 2.0 \\
Sulphur & 2.5 \\
Tetramethylthiuram disulphide (TMTD) & 1.0 \\
Mercarpto benzothiazole sulphenamide (MBTS) & 1.0 \\
Fillers (UC, CC and CB) & $0-50$ \\
\hline
\end{tabular}

\subsection{Preparation of the Fillers}

Coir: The crude coir obtained from the coconut shell was sun-dried. The material was then torn and ruffled to remove the lignin. In doing this, we used mortar and pestle to pound the sun-dried material so that the fibre is separated from mass of lignin (caution is needed not to grind the fibres at this stage). The coir so obtained was then dried in the oven at a temperature of $125^{\circ} \mathrm{C}$. The dried material was then divided into two parts. One part was ground using electrically powered plate grinding machine to attain fine particles size, (approximately 350 microns) obtainable with the machine locally employed. Graduated mesh sieves (180 - 600 micron) were used to determine the particle size of fillers.

The second part was then placed in a carbonising oven, which was properly sealed to avoid aeration (oxygen), which could subsequently cause ashing. An inert environment was created by the passage of Nitrogen gas through the carbonising oven. Cabonisation was done at a temperature of $800^{\circ} \mathrm{C}$. The material being charred (carbonised) was brought out and ground as in the previous case of the uncarbonised materials. Graduated mesh sieves were also used to determine the particle size (Table 2).

\subsection{Preparation of Composites}

The rubber was masticated and mixed with the additives using the two roll mill [22]. The filler loadings were varied from 0 to $50 \mathrm{phr}$ for both carbonised and uncarbonised coir. A separate set of composites was also prepared using carbon black as filler and also varied within the same range of filler loading. These three sets of composites were comparatively analysed in this work (Table 1 ).

\subsection{Vulcanisation}

Vulcanisation is a chemical process needed to transform the mechanical structure of rubber from visco-elastic and highly deformable to fairly rigid three-dimensional structure. The rubber composites were vulcanised in the laboratory press using different moulds and test pieces were cut for analyses. For instance, dumb bell shape is cut for tensile strength test and circular disc for abrasion test. Sulphur vulcanisation was done at a temperature of $140^{\circ} \mathrm{C}$ for five minutes.

\subsection{Characterisation of Fillers}

During this study, fillers characterisation was done using the following parameters: moisture content, ash content, loss on ignition, filler density, $\mathrm{pH}$ value, diameter and surface area (see Table 2).

\subsubsection{Moisture Content}

To determine the moisture content of fillers, a sample of each was placed in a crucible and weighed. Then it was placed in an oven maintained at temperature of $120^{\circ} \mathrm{C}$ and weighing was repeated at intervals of 10 minutes until constant weight was obtained for each of the fillers. In each case, cooling was done in desiccators before weighing.

\subsubsection{Computation of Moisture Content}

Weight of empty dish $=\mathrm{x}_{1}$; Weight of wet sample and dish $=\mathrm{x}_{2}$; Weigh of dried sample and dish $=\mathrm{x}_{3}$ 
Table 2. Fillers characteristics.

\begin{tabular}{cccc}
\hline Parameter & UC & CC & CB \\
\hline Moisture Content $(\mathrm{wt} \%)$ & 11.50 & 7.20 & 2.40 \\
Ash content $(\%)$ & 4.90 & 9.00 & 92.60 \\
Loss on ignition $\left(875^{\circ} \mathrm{C}\right)$ & 51.00 & 56.37 & 1.19 \\
Density $\left(\mathrm{g} / \mathrm{cm}^{3}\right)$ & 0.17 & 11.26 & 6.50 \\
$\mathrm{pH}$ & 6.18 & 520.00 & \\
Diameter $(\mu \mathrm{m})$ & 610.00 & 0.0097 & \\
Surface area $\left(\mathrm{m}^{2} \cdot \mathrm{g}^{-1}\right)$ & 0.058 & \\
\hline
\end{tabular}

Key: UC—Uncarbonised Coir; CC—Carbonised Coir; CB—Carbon Black.

$$
\begin{aligned}
\text { Moisture content } & =\frac{\text { Weight of wet sample-Weight of dried sample }}{\text { Weight of wet sample }} \times 100 \% \\
& =\frac{\left(x_{2}-x_{1}\right)-\left(x_{3}-x_{1}\right)}{\left(x_{2}-x_{1}\right)} \times 100 \%
\end{aligned}
$$

\subsubsection{Ash Content and Loss on Ignition}

Determination of ash content and loss on ignition were done as follows. A sample of the filler was placed in a crucible and weighed. Then the crucible and content were placed in an ashing kit maintained at a temperature of $875^{\circ} \mathrm{C}$. The heating was continued until fumes from the sample ceased.

\subsubsection{Computation}

Weight of empty crucible $=x_{1}$; Weight of crucible + sample $=x_{2}$; Weigh of crucible + ash $=x_{3}$

Ash content $\%=\frac{\text { Weight of ash }}{\text { Weight of sample }} \times 100 \%=\frac{\left(x_{3}-x_{1}\right)}{\left(x_{2}-x_{1}\right)} \times 100 \%$

Loss on ignition $\%=\frac{\text { Weight loss }}{\text { Weight of sample }} \times 100 \%$

\subsubsection{Filler Density}

Water was poured into a volumetric cylinder to a predetermined level of $250 \mathrm{ml}$, which was noted as $\mathrm{v}_{1}$. An empty density bottle with cap was weighed $\left(\mathrm{w}_{1}\right)$ and placed inside the cylinder. There was a rise in volume and the new volume was noted as $\mathrm{v}_{2}$.

The density bottle was removed, filled with filler, tightly closed and weighed. This weight was recorded as $\mathrm{w}_{2}$. Then the density bottle and its content were placed back into the cylinder and the new level of volume recorded as $\mathrm{v}_{3}$.

\subsubsection{Computation}

Weight of empty density bottle $=\mathrm{w}_{1}$; Weight of density bottle + filler $=\mathrm{w}_{2}$; Initial water level in cylinder $=\mathrm{v}_{1}$

Level of water on immersion of empty density bottle $=\mathrm{v}_{2}$

Level of water on immersion of density bottle with filler $=\mathrm{v}_{3}$

Weight of filler $=\mathrm{w}_{2}-\mathrm{w}_{1}$

Volume of filler $=\mathrm{v}_{3}-\mathrm{v}_{2}$

Density $=\frac{\text { Weight of filler }}{\text { Volume of filler }}=\frac{w_{2}-w_{1}}{v_{3}-v_{2}}$

\subsubsection{Determination of Filler $\mathrm{pH}$}

A predetermined quantity (5 g) of the filler was measured into beaker containing $100 \mathrm{ml}$ of distilled water kept 
at temperature range of $50^{\circ} \mathrm{C}-60^{\circ} \mathrm{C}$. This was stirred vigorously and then a $\mathrm{pH}$ indicator was used to determine the $\mathrm{pH}$ level of the slurry so formed. The $\mathrm{pH}$ was also read from a $\mathrm{pH}$ meter.

\subsubsection{Determination of Surface Area of Filler}

The particle size was estimated by the use of graduated sieves and the density determined as explained above, the surface area of filler was then computed using Equation (2), previously stated:

Surface area, $\mathrm{A}_{\mathrm{s}}=\frac{6000}{\rho d} \mathrm{~m}^{2} / \mathrm{g}$

where $\rho=\operatorname{density}\left(\mathrm{g} / \mathrm{cm}^{3}\right) ; d=$ particle diameter $(\mathrm{nm})$.

\subsubsection{Property Analyses of Composites}

After the preparation of composites, test pieces were prepared into different forms and shapes for various analyses and tests. The following properties were tested: Hardness, Tensile Strength, Elongation at break, Abrasion Resistance, Compression Set and Flex Fatigue, following standards [23]-[27].

\section{Results and Discussion}

Characterisation of the filler was done to enable a projection into what to expect from their effects on the polymer in question. The parameters investigated included: moisture content (\%), ash content (\%), loss on ignition, density, $\mathrm{pH}$, particle size and surface area. These parameters are determinants of the level of distribution and dispersion of fillers in rubber, which are manifested on the final products properties. This is in line with assertion of other researchers [7] [10].

For $\mathrm{pH}$ test, the values were found to be 6.18 and 11.26 for uncarbonised and carbonised coir respectively. From the values, we observed that carbonisation raised the $\mathrm{pH}$ of the fillers (See Table 1). It has been found that alkaline fillers increase the cure rates of vulcanisates as was also observed during this work. [3] [7] [10] [16] [28].

Loss on ignition is a property of filler that indicates the amount of carbon lost during combustion and it is a pointer to the effectiveness of the fillers. This parameter affects the level of distribution and dispersion of fillers in the rubber composites. High loss on ignition indicates high level of carbon content and subsequently high ability of the fillers to reinforce [10] [29]. However, the observation from our results did not quite go in that direction, as the UC induced higher reinforcement properties on the rubber composites than the CC (see Figures 1-3). Other factors, such as particle size, structure and nature of filler, which also affect the reinforcement potential of given fillers, could be responsible for this observation.

The result revealed a general effect of varying filler quantities on the physical properties tested during this study, which is an indication for reinforcement potential. It was also observed that the UC and CC exhibited different levels of reinforcement potentials.

There was a general trend of increasing hardness, tensile strength and modulus as filler quantities in the composites was increased (see Figures 1-3). This is as expected because when more filler volumes are incorporated into the rubber matrix, the composite becomes more rigid, as there is progressive reduction of rubber chain elasticity. The result further showed that rubber samples filled with the uncarbonised coir (UC) were better reinforced than those filled with carbonised coir (CC). This behaviour was attributed to the extreme temperature $\left(800^{\circ} \mathrm{C}\right)$ at which the coir was carbonized. At that temperature, the cellulose material (coir) would have been degraded and denatured, as such loses its power to reinforce.

Generally it was observed that the CB-filled composites have clearly higher values of hardness, tensile strength and modulus for various filler volumes than those of UC and CC-filled composites (Figures 1-3). But the results for hardness were sufficient for us to assert that UC and CC have potential for reinforcement and that they maintained similar trends with the commercial filler (CB) used, since their hardness rated above $50 \%$ of the results obtained for carbon black reinforced products. (Figure 1) For example, the hardness values obtained for samples at filler volume of $50 \mathrm{phr}$ were compared using those of CB filled vulcanisates as reference point $(55$ IRHD $=100 \%)$, and the following results were obtained: 50IRHD (90.9\%) for UC and 38IRHD (69.1\%) for CC.

However, for tensile strength and modulus tests of composites, the results increased slightly with increments in filler quantity for the UC and CC. This property behaviour can be explained by the fact that adhesion oc- 


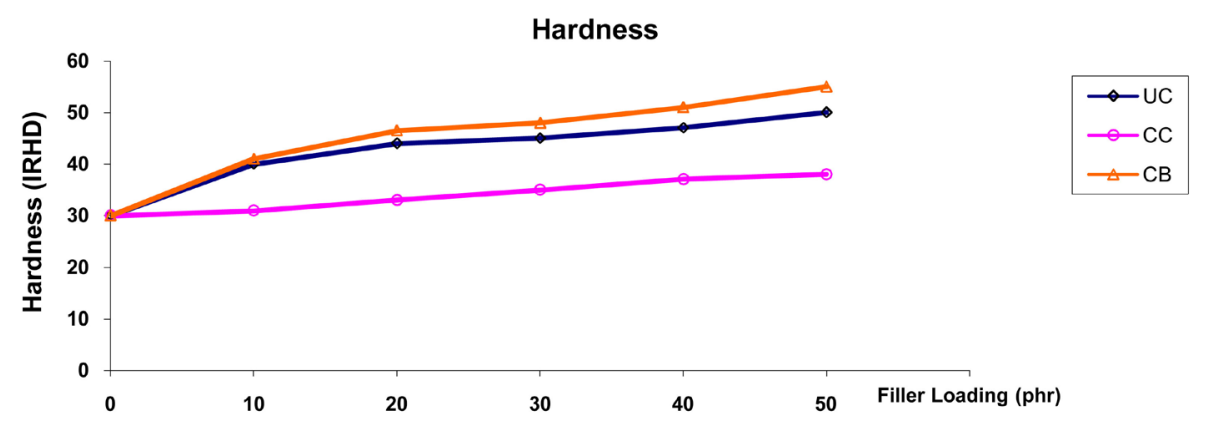

Figure 1. Effect of filler loading on hardness.

Tensile Strength

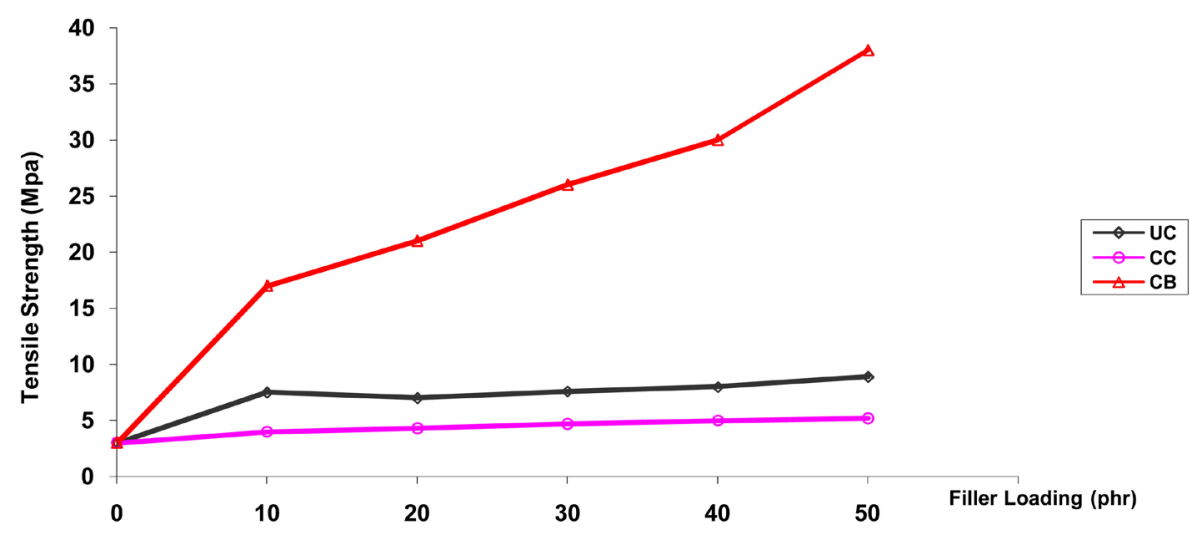

Figure 2. Effect of filler loading on tensile strength of rubber composites.

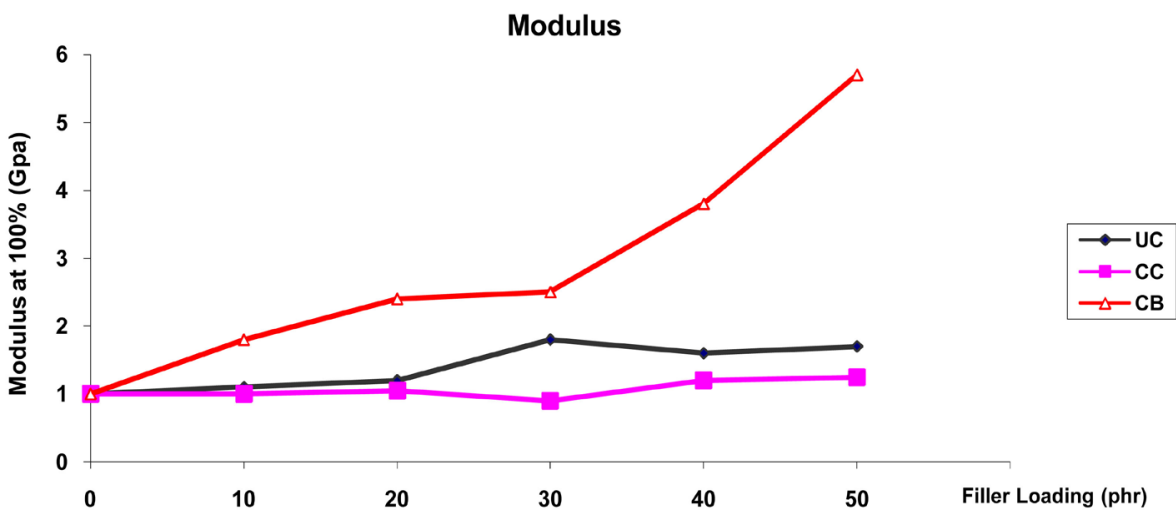

Figure 3. Effect of filler loading on modulus of rubber.

curred between the filler and the rubber matrix, which led to the increase in stiffness, rigidity, strength and modulus. The behaviour could also be explained on the basis of filler properties. The graphs of property against filler volume were almost parallel to the $\mathrm{x}$-axis signifying low increase in strength as filler volume was increased. The values were also very low when compared to the tensile strength and modulus obtained from the CB filled composites, where the rising trend was clear (Figure 2 and Figure 3). This observation was in agreement with those of other previous researchers [30]-[33].

The poor reinforcements as was observed were attributed to the large particle size, nature, structure and low surface activity of the agricultural waste fillers (UC and CC) as used in this study, compared to the particle size and other properties of CB [10] [14] [16] [34] [35]. Reduction of particles size of CB was found to enhance the mechanical properties like tensile strength [30]. Another reason is that the agricultural waste fillers have more 
tendencies for filler agglomeration, making dispersion and distribution in the matrix more difficult. If the surface properties of fillers such as surface area, surface reactivity, filler dispersion and filler-rubber interaction are modified, the modulus of filled rubber vulcanisates can be significantly enhanced.

The results for the compression set, elongation at break and flex fatigue, as presented in Figures 4-6 were observed to take a falling trend as the filler volume was increased. This trend was similar for all the test samples. The carbon black filled vulcanisates also had the same trend and maintained the lowest values in each case of filler volume. This observation may be connected with the amount of filler incorporated into the Rubber matrix, the particle size of fillers and their extents of dispersion. As more filler are put in the rubber matrix it becomes more rigid and less susceptible to compression loading, elongation and exhibit low flex. High values of compression, elongation and flex are indications for less reinforcement (Figures 4-6).

The unfilled sample had the highest value of compression, elongation at break and flex, while the CB filled samples had the least values for each case of filler volume. We linked this behaviour with the adherence of the fillers to the polymer phase, which caused the stiffening of the rubber chains and thus exhibited as resistance to compressive, tensile and flex loading under applied strain. This claim was found in agreement with observations in our previous research [7] and of other researchers [10] [20] [36]-[38].

From the results of abrasion resistance displayed by all the test samples we observed that increasing filler volume did not continuously increase the abrasion resistance index of the composites and so did not have significant effect on this property (Figure 7). The irregular behaviour could be connected to a reason that as the filler volume is increased, the adhesion strength between polymer and fillers falls.

\section{Conclusions}

In this study, being motivated by the drive to search from renewable sources for possible alternatives or complements to carbon black as compounding filler for polymer products, UC and CC were comparatively investigated as fillers in NR composites. Success in this direction is expected to reduce the pressure on fillers which are

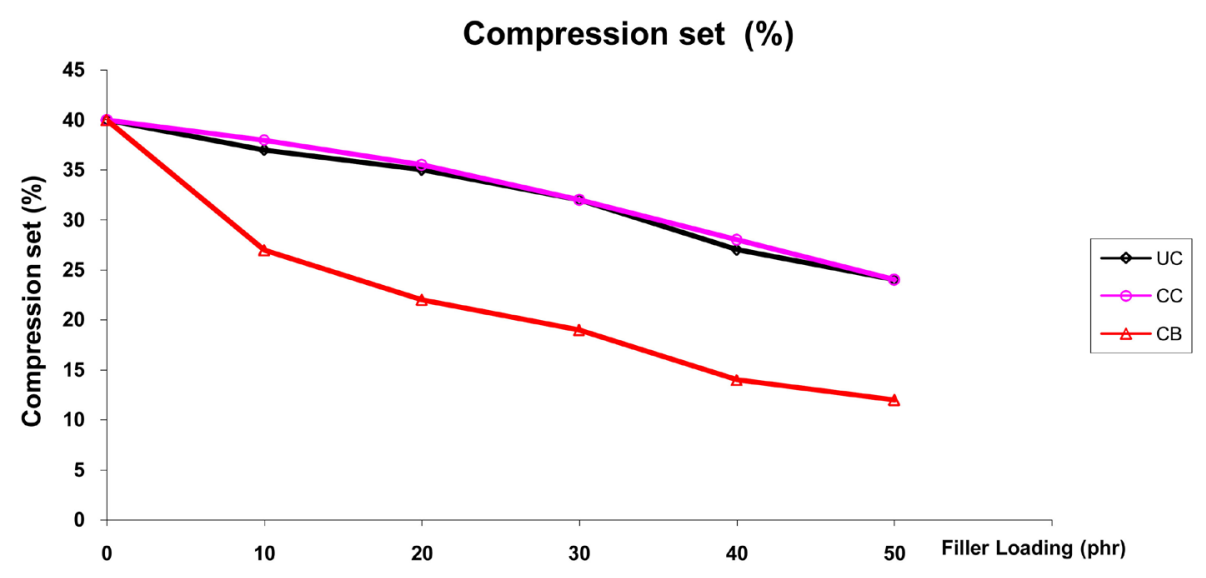

Figure 4. Effect of filler loading on compression set.

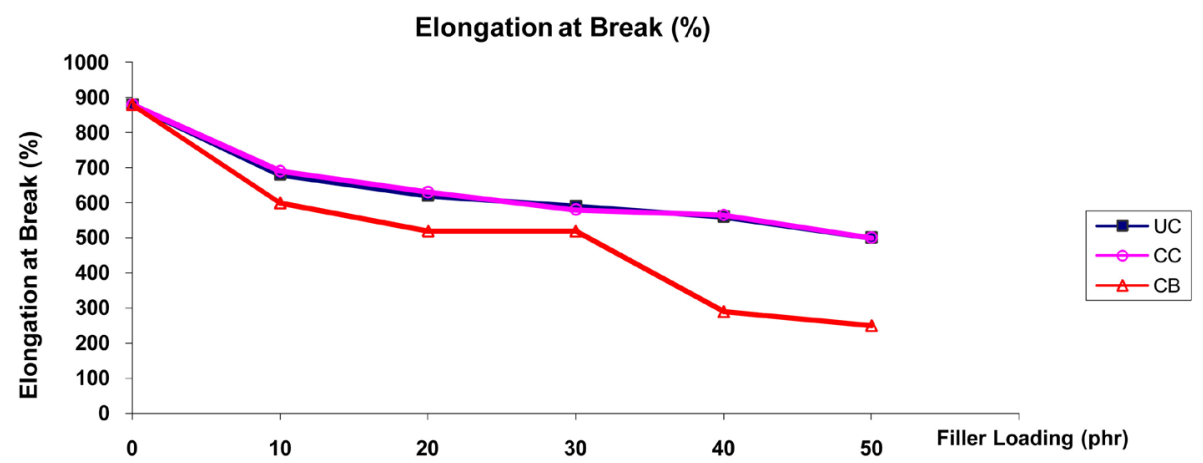

Figure 5. Effect of filler loading on elongation at break of rubber composites. 


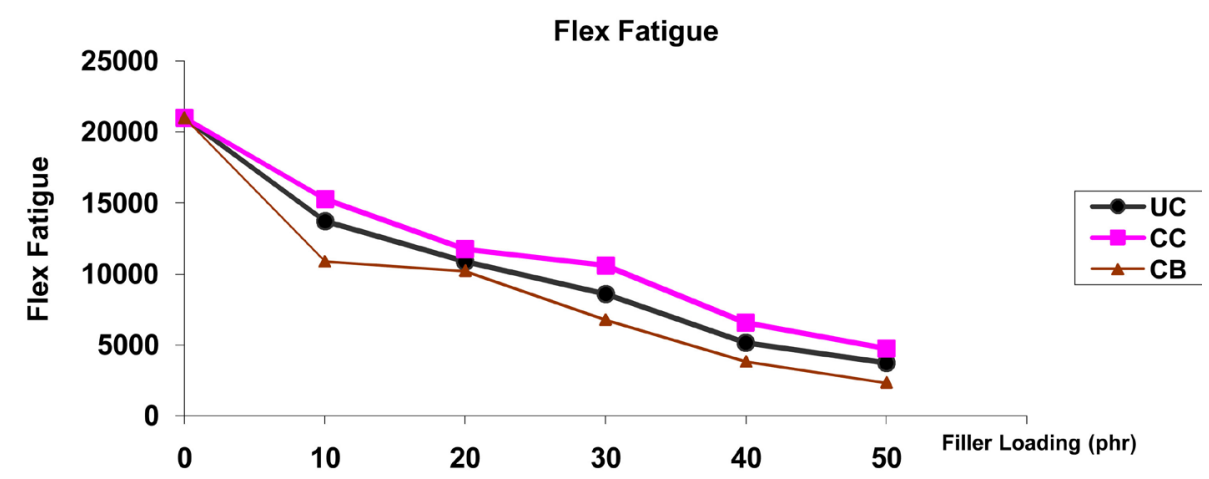

Figure 6. Effect of filler loading on flex fatigue of rubber composites.

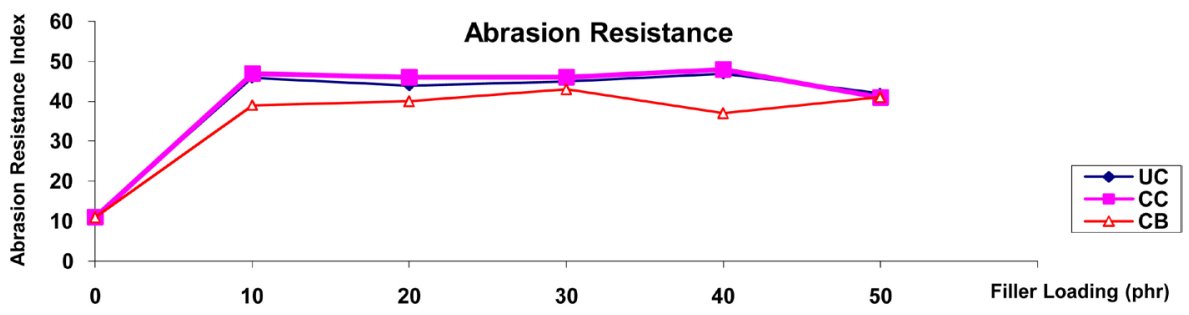

Figure 7. Effect of filler loading on abrasion resistance index of rubber composites.

obtained from petroleum by-products. The cost of rubber products would be lowered and subsequently their availability would also be enhanced.

Though a general potential for reinforcement was observed for both UC and CC as evidenced from the results obtained during this study, the reinforcement potential was more in uncarbonised (UC) than the carbonised (CC) fillers; this observation as was made in this study had earlier been attributed to the use of excessive carbonisation temperature $\left(800^{\circ} \mathrm{C}\right)$, which had degraded the agro-based filler before use.

We recommend that carbonisation should be done at a lower temperature. That modification may be done on the fillers, such as control of surface activities, particle size, distribution and dispersion; and also a modification of filler-matrix interactions by way of compatibiliser and/or coupling agent, would further improve the reinforcement potentials achievable from the fillers.

\section{References}

[1] Michael Ashby, F. and David Jones, R.H. (1998) Engineering Materials 2. An Introduction to Microstructures, Processing and Design. 2nd Edition. Butterworth-Heinemann, Oxford.

[2] Katchy, E.M. (2000) Introduction to Polymer Technology. 1st Edition, El Demark, Enugu.

[3] Asore, E.J. (2000) An Introduction to Rubber Technology. Joseg Books, Benin City.

[4] Peply, H.E. (1987) Engineered Materials Handbook. ASM International, Ohio.

[5] Herakovich, C.T. (1998) Mechanics of Fibrous Composites. John Wiley and Sons Inc., New York.

[6] Akovali, G. and Uyanik, N. (2001) Handbook of Composite Fabrication. Rapra Tech Ltd., Shrewsbury.

[7] Aguele, F.O. and Madufor, C.I. (2012) Effects of Carbonised Coir on Physical Properties of Natural Rubber Composites. American Journal of Polymer Science, 2, 28-34. http://dx.doi.org/10.5923/j.ajps.20120203.02

[8] Brydson, J.A. (1985) Plastic Materials. 4th Edition, Butterworth, London.

[9] Rowell, R.M. (1998) Property Enhanced Natural Fibre Composite Material Based on Chemical Modification. Science and Technology of Polymer and Advanced Material. Plenum Press, New York.

[10] Egwakhide, P.A., Akporhonor, E.E. and Okieimen, F.E. (2007) Effect of Coconut Fibre Filler on the Cure Characteristics, Physico-Mechanical and Swelling Properties of Natural Rubber Vulcanisates. International Journal of Physical Sciences, 2, 39.

[11] Ski, K.B. (1970) Engineering Materials. Properties and Selection. Reston Publishing, New York. 
[12] Honday, L. (1966) Composite Materials. Elsevier, New York.

[13] Billmeyer, F.W. (1970) A Textbook of Polymer Science. John Wiley and Sons, New York.

[14] Bhatnagar, M.S. (2004) A Textbook of Polymers: Chemistry and Technology of Polymers. Processing and Applications, Vol. II. 1st Edition, S Chand, New Delhi.

[15] Cain, M.E. (1974) Engineering Design with Natural Rubber. Malaysian Rubber Producers’ Research Association, Hertford, England.

[16] Kumar, A. and Gupta, R.K. (1998) Fundamentals of Polymers. International Edition, McGraw Hill, Singapore.

[17] Drivers, W.E. (1979) Plastic Chemistry and Technology. Van Nostrand, London.

[18] Boonstra, B.B. (1971) Rubber Technology and Manufacture. Blow, C.M., Ed., 3rd Edition, Butterworth, London, 227.

[19] Wafwoyo, W., Seo, C.W. and Marshall, W.E. (2001) Utilization of Peanut Shells as Adsorbents for Selected Metals. Journal of Chemical Technology and Biotechnology, 74, 1117-1121. http://dx.doi.org/10.1002/(SICI)1097-4660(199911)74:11<1117::AID-JCTB151>3.0.CO;2-R

[20] Okieimen, F.E. and Imanah, J.E. (2005) Physico-Mechanical and Equilibrium Swelling Properties of Natural Rubber Filled with Rubber Seed Shell Carbon. Journal of Polymer Materials, 22, 409.

[21] Adeosun, B.F. (2000) Mechanical and Rheological Properties of Natural Rubber Composites Reinforced with Agricultural Wastes. Nigerian Journal of Polymer Science and Technology, 1, 58-62.

[22] ASTM-D3184-80 (1983) Standard Attest Method for Compounding Rubber.

[23] ASTM-D1415-06 (2012) Standard Test Methods for Rubber Property-Hardness.

[24] ASTM-412 (2011) Standard Test Methods for Rubber Property-Tensile Strength and Elongation.

[25] ASTM-5963-04 (2010) Standard Test Methods for Rubber Property-Abrasion Resistance.

[26] ASTM-D395-03 (2008) Standard Test Methods for Rubber Property-Compression Set.

[27] ASTM-D430 (2012) Standard Test Methods for Rubber Property—Flex Fatigue.

[28] Horn, J.B. (1971) Rubber Technology and Manufacture. Blow, C.M., Ed., 3rd Edition, Butterworth, London.

[29] Okieimen, F.E. and Imanah, J.E. (2003) Characterization of Agricultural Waste Products as Fillers in Natural Rubber Formulations. Nigerian Journal of Polymer Science and Technology, 3, 201.

[30] Parkinson, D. (1957) Reinforcement of Rubbers. Lakeman and Co., London, 12.

[31] Wagner, M.P. (1976) Silicone Rubber Compositions Incorporating Silicone Treated Carbon Black. Rubber Chemistry and Technology, 50, 342.

[32] Cohan, L.H. and Spielman, R. (1948) Inorganic Pigments in Natural and Synthetic Rubber. Industrial \& Engineering Chemistry, 40, 2204-2210. http://dx.doi.org/10.1021/ie50467a042

[33] Oguniyi, D.S. (1989) CaCO3 as Filler in Rubbers. Nigerian Journal of Applied Sciences, 7, 87.

[34] Morton, M. (1987) Rubber Technology. 3rd Edition, Van Nostrand, New York.

[35] Patterman, M.Q. (1986) Chemorheology of Model Filled Rubber Compound during Curing. Rubber World, $194,38$.

[36] Ishak, Z.A.M. and Bakar, A.A. (1995) An Investigation on the Potential of Rice Husk Ash as Fillers for Epoxidised Natural Rubber. European Polymer Journal, 31, 259-269. http://dx.doi.org/10.1016/0014-3057(94)00156-1

[37] Hephburm, C. (1971) Rubber Technology and Manufacture. Blow, C.M., Ed., 3rd Edition, Butterworth, London, 188.

[38] Rivin, D. (1963) Polymer-Filler Interaction in Rubber Reinforcement. Rubber Chemistry and Technology, 36, 729. 
Scientific Research Publishing (SCIRP) is one of the largest Open Access journal publishers. It is currently publishing more than 200 open access, online, peer-reviewed journals covering a wide range of academic disciplines. SCIRP serves the worldwide academic communities and contributes to the progress and application of science with its publication.

Other selected journals from SCIRP are listed as below. Submit your manuscript to us via either submit@scirp.org or Online Submission Portal.
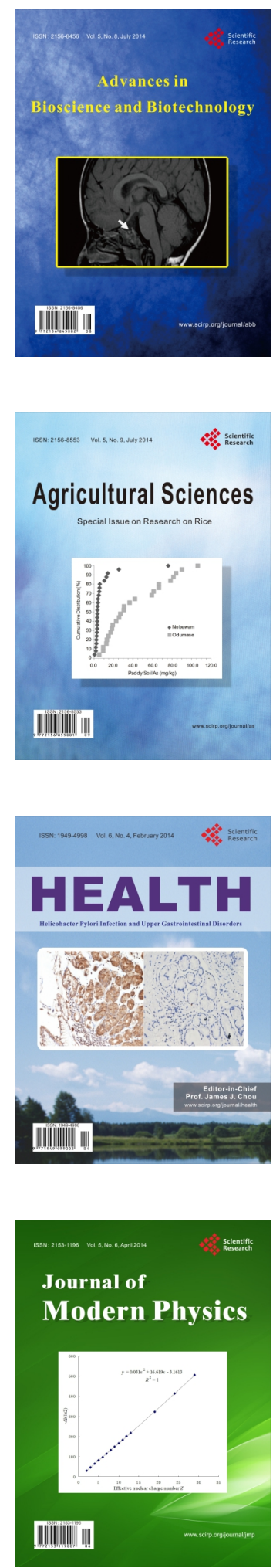
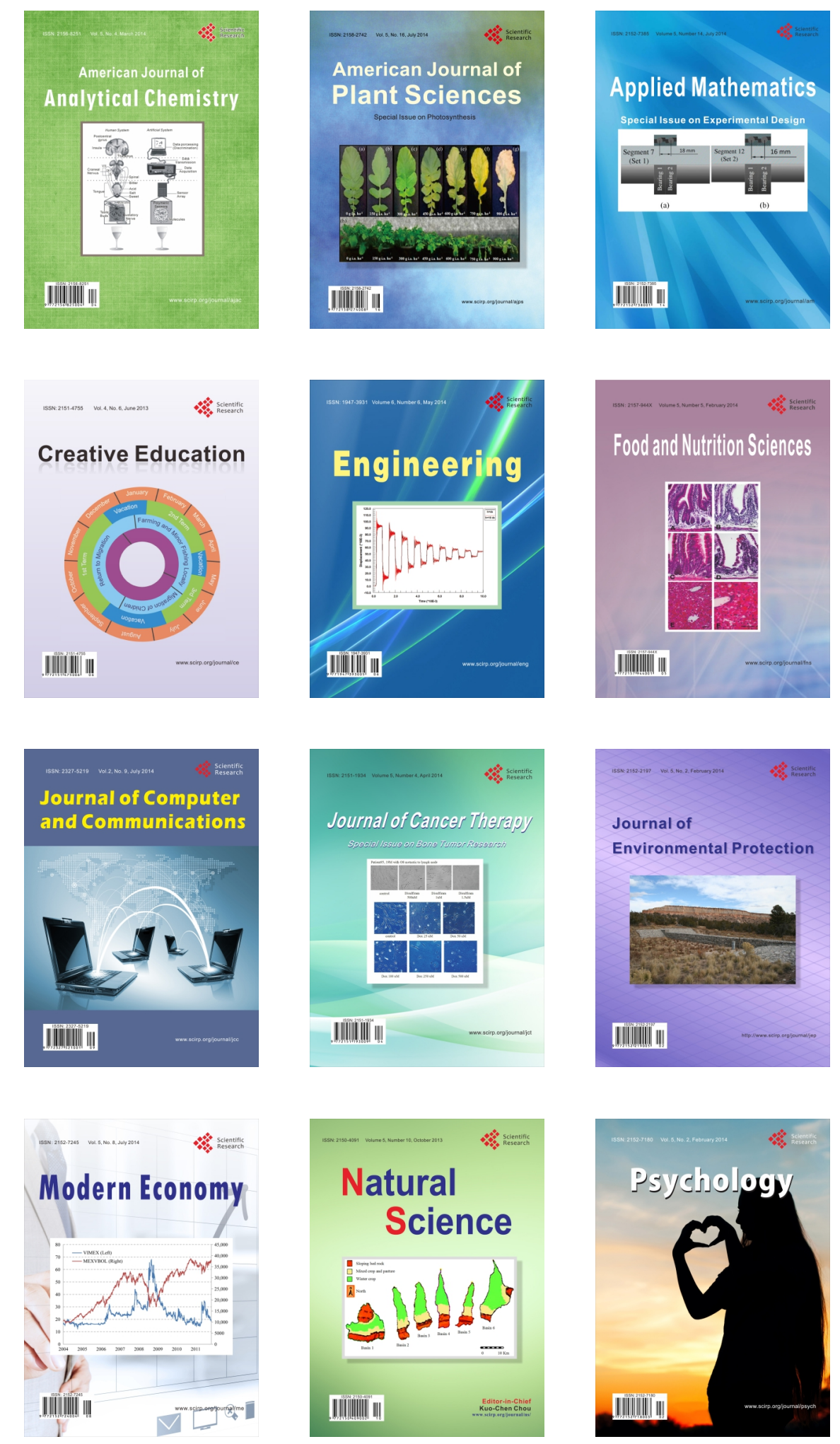